\title{
Contraceptive Practices in Finland in 1971
}

KIMMO LEPPO

OSMO KOSKELAINEN

KAI SIEVERS

\section{Introduction}

This paper is a short report from a part of a study called "Sexual behaviour and contraceptive practices of the Finnish adult population». The scope and methods of the research project have been described in detail in other papers by the present authors (Sievers et al. 1971, 1972, 1973; Koskelainen et al. 1972; Leppo et al. 1973), and therefore we would like to deal here only in the briefest way possible with some salient features of the research project.

The main purpose of the study has been to describe, explain and interpret patterns of sexual behaviour and contraceptive practices in the light of sociological, psychological and medical factors, with special reference to the implications of the findings for society and for public policy-making. The field work for data collection was carried out after three careful pilot surveys in November -December 1971. A probability sample of 2492 persons (912 males and 1490 females) aged 18 to 54 was drawn from the official Population Register by a systematic (equal interval) technique, weighting females in the fertile age group (18 to 44 ) doubly to their proportion among the general population. The material was collected through personal visits by about 1000 public health nurses and midwives, who had been trained in 28 one-day sessions by the members of the research team. A combined interview-questionnaire method of data collection was used in a way that was first applied succesfully in this kind of study by Zetterberg (1969) in Sweden. The interviews started as normal face-to-face interviews, but all the delicate and embarassing questions (including all sexual items, a full pregnancy history, as well as contraceptive practices) were presented in a self-administered questionnaire, which was filled in the presence of the interviewer but so that the latter came to know nothing about the respondent's answers to these questions. Absolute anonymity and confidentiality of the records was guaranteed by various safety procedures. The average duration of the interviews was about $1 \frac{1 / 2}{2}$ hours. The interviewers performed their work admirably and the respondents reacted quite favorably: only 8 per cent of the persons eligible were not or could not be interviewed. Among married women aged 18 to 44 non-response was even lower, 6 per cent. The sample is, of course, too small for multivariate tabulations due to the small numbers of cases in the cells. The sample is, however, well representative of the Finnish 
adult population in regard to demographic and social characteristics, and has withstood rather rigorous checks of reliability wherever possible (Leppo et al. 1973), with one exception. The data concerning abortion are deficient as in earlier surveys (see Acsadi et al. 1969), the incidence figures on this topic being clearly underestimates, and they will be left out of consideration in this paper.

The final report, which is now in print (Sievers et al. 1974), contains one chapter on knowledge, attitudes and practices of fertility regulation both of married and non-married males and females. In the following discussion, however, after introductory findings related to the whole Finnish adult population we restrict ourselves mainly to the group of currently married women aged 18 to 44 . The reasons for restricting the present discussion mainly to marital contraception are simply 1) the need to make the presentation less ramified, 2) the fact that in terms of fertility this group is the central focus of interest in all demographic research, and that 3) the data concerning married women include a number of the characteristics of the partner, whereas this kind of information is scantier in the case of non-married people in our material.

Parts of the results presented in this paper have appeared in another form in an earlier preliminary report (Leppo et al. 1973), which was based on the tabulations prepared according to the standard tabulation programme of the Population Team of UN/ECE for the comparative study of fertility and family planning in Europe around 1970. The slight difference in some figures of the former and the present paper are due to different definitions of the population studied as well as some differences in classification.

\section{The Need for Research into Differential Use of Contraception}

There are two main reasons for studying contraceptive practices. The first one is pragmatic and related to social policy: it is expected that more detailed knowledge about patterns of fertility regulation would give some guidelines for better public action and services in the field. Public information, civic education and personal health services probably have a better chance to succeed in their efforts towards effective contraception and diminishing the need to use abortion as a means of fertility regulation, if these efforts are based on a sound knowledge and evaluation of the existing situation and its deficiencies.

The second reason for research into contraceptive behaviour is more theoretical and related to a focal point in current social demography: the sociological theory of differential fertility. It has been a common practice in fertility and family planning surveys to stress the importance of values, ideals and norms concerning the number and spacing of children as determinants of differential fertility. This approach has its drawbacks, however, especially in retrospective surveys like most KAP-studies are. At least in our material, a minority of people actually at the time of marriage had a fixed or crystallized idea of the number of children they wanted (see Visuri \& Ritamies 1973). In 
addition, it is quite probable, that post factum rationalizations enter into the number of children desired (Ryder \& Westoff 1971, 92-95) and diminish the validity of this approach. The case for an alternative approach has been succintly stated by Ryder: "I think the results of a generation of fertility research suggest that variations in parity are more likely to reflect variations in the efficacy of fertility regulation than variations in intention» (Ryder 1973, 68). If this is true, it is important to study the differential use of contraception in various subgroups of the population, and this is what this paper aims at: to give a general description of the contraceptive practices of different Finnish population groups, with special reference to the variation in the efficacy of the methods used and the implications therein. Three themes are covered in this paper: first, ever-used methods of contraception, secondly, the distribution of population groups into different categories of conception control according to the risk of pregnancy and the contraceptive methods currently used, and thirdly, some findings about the regularity of use of contraception. These simple measures of contraceptive practices are crosstabulated with social and demographic background variables to give a general view of the existing differences and similarities in contraceptive behaviour.

\section{Ever-used Methods of Conception Control}

Percentages showing ever-used contraceptive methods in different population groups are given in Table 1 (p. 55). The figures refer to the whole Finnish population aged 18 to 54 and having had sexual intercourse. The first notable fact in Table 1 is the first column showing the percentage of people who have no experience of any contraceptive methods whatsoever. The total non-use of contraception rises with religiosity of the respondent, with low education, low income, and age. The three methods of which most Finnish people have experience are the condom (sheath), withdrawal and the pill, in this order of frequency. The rural-urban differences are small, with slightly higher figures for condom and pill use in urban areas. Religiosity of the respondent causes a rather small difference to the method chosen, if allowance is made for the greater non-use of contraception in the religious group. The only marked difference by method is the clearly lower figure for pill use among religious people. The reason for this is not the higher average age of religious women, because the difference persists after a control for age (Sievers et al. 1974).

The better educated people show higher life-time incidences for all contraceptive methods except withdrawal, and the same holds for well-to-do people compared to low-income groups. The most drastic variation can be seen in the use of the pill, the IUD and the diaphragm in different income groups. The incidence of pill use is about double in the highest income quartile compared with the lowest one; in regard to diaphragm the use-ratio is four-fold and in regard to IUD five-fold. The break-downs related to age show some interesting 
features. The use of condom and the pill have been increasing, and the young generation is putting on the shelf of history even that little use of diaphragm which has existed.

In comparison with the recent Danish data on the same topic (Ussing \& Bruun-Schmidt 1972, 70-71), the main differences seem to lie in a much lower incidence of the use of diaphragm and a clearly higher incidence of withdrawal and condom use in Finland. The figures concerning the use of pill and the IUD are at about the same level.

The general lesson from Table 1 is the following: better-off people show higher incidences of having used contraceptive methods which require medical attention, but they also report more often use of conventional methods, and therefore show a wider armament and variation in their conception control. The latter generalization applies also to the younger generation when compared with the older one, especially if the difference in time of exposure is taken into account. Thus, contraceptive knowledge and practice can be seen as one aspect or indicator of the disposable resources of the individual or the couple.

\section{Categories of Conception Control and Currently Used Methods of Contraception}

Listing of ever-used methods of contraception measures only the life-time incidences and tells quite little of the use of methods in relation to the need or the exposure to the risk of unintended pregnancy. More light on these topics is given in Table 2 (p. 56), which shows the prevalence of current exposure to conception as well as the methods currently (during the month preceding the interview) used among the whole female population aged 18 to 44 .

Women in this fertile age group have first been classified according to the need of contraception. If the woman has not ever or during the last month had sexual intercourse, there is of course no need for contraception. The same applies to women who cannot get pregnant (are non-fecund) or who are pregnant at the time of the interview, or who are trying to get pregnant. Women who neither belong to any of the groups mentioned, nor have practised any form of contraception, form a group subjected to a high risk of unintended pregnancy. A third group of women consists of those who have used some method of conception control during the last month, and they have further been classified according to the method used in the seven columns at the right hand side of Table 2. Women reporting the use of more than one methods have been classified according to the more reliable method. This together with the fact that the regularity of use of contraception has not been taken into account, gives an overestimated view of the effectiveness of fertility regulation. It suffices however for the purpose of giving a general description of the prevalence of conception control categories and methods among the whole female population in the fertile age group. 
Of all women aged 18 to 44 years, 36 per cent had no need of contraception, 61 per cent had used some method during the month preceding the interview, and about 3 per cent had had intercourse totally without any form of contraception. The most prevalent methods were the condom, the pill and withdrawal. These same methods were leading the list of ever-used methods of contraception, and can therefore be said to clearly dominate the Finnish contraceptive culture.

The breakdown by age shows differences which are by no means unexpected, but clear and consistent enough to deserve attention. The condom is the most prevalent method in all age groups except the women aged 21 to 24 , of whom 29 per cent are taking pills. The prevalence of the pill decreases with age and varies conversely with the use of withdrawal. It is rather certain, that the younger cohorts will not resort to withdrawal while they grow older, whereas a large part of the older cohorts have probably used it throught their lives. The magnitude of the age-specific differences can be said to reflect a really impressive cultural change caused by the new contraceptive technology.

The distributions according to social background characteristics show clear differences especially in the use of withdrawal, which is much less prevalent among the better educated and middle-class strata. Non-use of contraception seems to concentrate into the same groups as the use of withdrawal. The regional differences at the level of administrative provinces which are considerable in general socio-economic characteristics) are surprisingly small. One can reasonably characterize Finland as a uniform contraceptive culture in regard to regional considerations, but as rather clearly differentiated contraceptive cultures, if one thinks in terms of age groups or social classes.

For a more detailed picture we go on to Table 3 (p. 58), which shows the currently used contraceptive methods among married women aged 18 to 44 . Again we see that the use of pills decreases sharply with increasing age but there is no clear association with education and income level. The latter finding is in striking contrast with the figures of Table 1 . The difference between the incidence of life-time use and the prevalence of current use of oral contraception could possibly reflect a social differential in the adoption and discontinutation of this contraceptive method. We have no data of the time of starting and ending the use of oral contraception, but presumably the use of the pill is no exception to the general rule that innovations are first adopted by the well-to-do and better educated strata, and spread gradually to other social groups. In this case it could be hypothesized that the upper strata first have adopted the practice of oral contraception, but would also have been the first ones to discontinue its use because of the widely publicized and discussed health hazards of oral contraceptives. In other words, the use of the pill would be in its height or even increasing in lower strata at the same time as it has already declined in the upper strata. This is one of the possible mechanisms that could produce the difference in the incidence and prevalence figures, but it remains rather speculative at this stage in lack of evidence. It is supported, however, 
by the finding that women in upper strata clearly more often than others reported health hazards as a factor of inconvenience in contraception, when this was specifically asked (Sievers et al. 1974).

The second interesting finding in Table 3 is again the remarkable variation in the use of withdrawal as the current method of contraception. There is a strong social gradient in the practice of coitus interruptus, with a clear preponderance in older age, rural areas, the less educated and low-income groups. The practice of withdrawal is widespread even among the couples who desire no more children and would be expected to use effective contraception: almost 20 per cent of these rely on withdrawal alone, with a high preponderance again among the less-educated people. These figures give a much worse impression of the proportion of couples "currently at risk» than the 3 per cent quoted above.

The third point worth mentioning in Table 3 is the confirmation of the differential distribution of contraceptive methods requiring special medical attention, which was anticipated in Table 1. Especially the IUD and to some extent the diaphragm as well seem to be more prevalent at the high income level, although not very common in this group either. Considering the distribution of the use of the IUD, one can only conclude that it is less influenced by the need than the ability to use the special services required for fitting it. Clearly, there is a great need to expand these services, as recently outlined in the recommendations of the National Board of Health in a circular letter concerning the organisation of guidance in fertility regulation within the context of basic health services in communal health centres (National Board of Health 1972).

The fourth finding in Table 3 deserving attention is the use of condom as a contraceptive. It is still the most commonly used method even among married couples in almost all sub-groups of the population, showing rather small differences between different categories of people, with one clear exception: the lowest income group makes less use of the condom and relies on withdrawal as often.

The husband-wife interaction and communication are beautifully reflected in Table 3. The couples among whom communication about sexual matters is difficult or impossible make less use of condom or pills and more often resort to withdrawal instead. This clearly reminds of Rainwater's findings concerning role-segregation and deficient communication as an obstacle to effective contraception (Rainwater 1965, 1968).

In summary, Tables 2 and 3 show that the Finnish contraceptive culture is dominated by the condom, the pill and the use of withdrawal, the latter being clearly more prevalent among the less privileged social groups. The reliance on withdrawal seems to be definitely more common in Finland than in Denmark (Ussing \& Bruun-Schmidt 1972, 73), but comparison with Swedish data (Zetterberg 1969,70 ) is impossible due to differences in tabulation. The proportion of couples currently at risk of unintended pregnancy because of nonuse of con- 
traception is rather small, especially in the groups where an additional pregnancy would be least desired. But because of the differences in the reliability of various contraceptive methods and the variation in the use of less and more reliable methods in different sub-groups of the population, a closer look at the concept of being »at risk» is warranted.

\section{Differentials in the Effectiveness of Contraception}

The measure of »currently at risk» introduced in the preceding discussion included only nonusers of contraceptive methods who did not belong to the "no risk» group. Considering the risk of unintended pregnancy attention should be paid not only to whether contraception is practised but as well to the effectiveness of the methods used: the pregnancy risk in using the pill is very different from that in withdrawal, for example. Therefore, we have produced Table 4 (p. 59), to show the differential distribution of population groups according to the effectiveness of contraception practised, which is inverse to the risk level of unintended pregnancy.

The concept of "currently at risk» is elaborated as follows. First, the category of "no risk» is left out of consideration, because the effectiveness of contraception is irrelevant to them. Then, the percentage of nonusers and users of contraception are calculated taking into account the reliability of the method used. The pill and the IUD are classified as highly reliable methods with no risk of conception, the diaphragm, the condom and the chemicals as rather reliable methods with low risk of conception, and withdrawal and rhythm as unreliable methods with medium risk of conception. Those using no method at all are classified as having a high risk of conception.

The most interesting features in Table 4 are the rather high prevalence figures of less reliable methods used in the lowest income group, and among those who want no more children. Of the latter group, in which one would need really effective contraception, 34 per cent of the less-educated and 17 per cent of the better-educated are under a considerable risk of unwanted pregnancy. The income differentials show rather small differences between the two middle categories, but the low and high income group differ from these medium classes. The proportion of couples using either no method at all or an unreliable one is 35 per cent in the lowest income group and 18 in the highest. In general, in the light of Table 4 there seems to be still much space for improvement of contraceptive effectiveness even in a country showing one of the lowest birth rates in the world. This impression is very much strengthened when the regularity of use of contraception is taken into account. Of the couples using condom 23 per cent had taken risks at least in one coitus during the last month, and the respective figure for those reporting use of withdrawal was as high as 29 per cent. Even in these figures a clear social gradient could be seen, with a more careful use among the upper and middle classes (Sievers et al. 1974). 
The study has revealed that there exist rather clear-cut differences in contraceptive practices between different sub-groups of the population. These differences are probably large enough to produce considerable differentials in the amount of unintended and unwanted pregnancies between various social categories. The figures in Table 4 would suggest that the lowest incidence of unintended fertility could be expected among the social elite, and the greatest figures in the lowest income group, the position of the middle classes being difficult to predict. The next thing to do, then, was to study whether this is what really has happened. The pregnancy history of the women studied included for each pregnancy a question whether conception happened after waiting for a long time, about the time wanted, before it was planned, or when no child was planned either then or later. From these data the success and failure in timing and limiting the conceptions have been calculated with breakdowns by different social categories. The figures for failures in the limiting and timing of pregnancies are astonishingly high, as in the American and British studies (Bumpass \& Westoff 1969, Cartwright 1970). The results concerning social differentials in this respect strongly support the suggestion outlined above, and have been reported in chapter 7 of the main volume of the research project (Sievers et al. 1974).

\section{Summary and Conclusions}

Results concerning the contraceptive practices of Finnish adults aged 18 to 54 are reported from a national probability sample survey on sexual behaviour and contraceptive practices. Ever-used methods of contraception, currently used methods of contraception in different categories of exposure to conception, and the level of effectiveness of the currently used contraception are broken down by basic social and demographic background variables (Tables $1-4)$. The emerging picture is one of a nearly universal use of contraceptive methods, rather clear-cut social differentials in the types of contraception used, and a contraceptive culture dominated by the condom, the pill and coitus interruptus. The social differentials shown in the effectiveness of contraception would be expected to produce sizeable differences between various social categories in unintended and unwanted fertility. This suggestion has been supported by analyses of the pregnancy histories, which have been reported elsewhere by the present authors. The main policy implication of the results presented in this paper is the following. If the value premise is accepted, that conceptions should happen by choice rather than by chance, there is still much to be done in terms of guidance and services required for effective contraception. If pronatal policy measures will be adopted for some purposes, the fact should not be forgot that at the same time a sore need exists for better antinatal practices in some sub-groups of the population. 
Table 1. Ever-used methods of contraception of the Finnish adult population. Percentages by row refer to all respondents aged 18 to 54 who have ever had sexual intercourse. All men and women aged 44 to 54 are weighted by 2.0 to correct the sampling weights. Question: "What birth control methods have you or your partner(s) used? Circle all methods with which you have experience».

\begin{tabular}{|c|c|c|c|c|c|c|c|c|c|c|c|}
\hline & 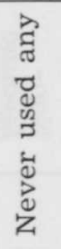 & 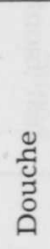 & 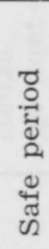 & 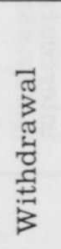 & 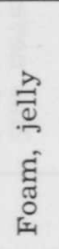 & 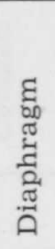 & 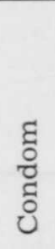 & S & $\exists$ & 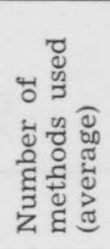 & z \\
\hline Total & 13 & 4 & 22 & 56 & 15 & 4 & 71 & 5 & 38 & 2.2 & 2836 \\
\hline Sex: male & 11 & 5 & 26 & 55 & 16 & 4 & 76 & 7 & 42 & 2.3 & 1376 \\
\hline female & 15 & 3 & 18 & 56 & 14 & 4 & 66 & 3 & 34 & 2.0 & 1460 \\
\hline Age: $18-29$ & 6 & 4 & 19 & 56 & 14 & 1 & 85 & 5 & 51 & 2.4 & 1164 \\
\hline $30-44$ & 11 & 3 & 26 & 58 & 21 & 6 & 71 & 7 & 40 & 2.3 & 1038 \\
\hline $45-54$ & 29 & 4 & 21 & 57 & 8 & 6 & 45 & 1 & 10 & 1.5 & 634 \\
\hline
\end{tabular}

Years of schooling:

$\begin{array}{crrrrrrrrrrr}-8 & 19 & 9 & 18 & 54 & 11 & 3 & 61 & 4 & 28 & 1.9 & 1606 \\ 9-11 & 7 & 4 & 20 & 54 & 17 & 5 & 80 & 4 & 45 & 2.3 & 716 \\ 12+ & 5 & 6 & 35 & 63 & 23 & 5 & 87 & 8 & 57 & 2.8 & 514\end{array}$

Class identification:

Upper or middle

class

$\begin{array}{lllllllllll}8 & 5 & 31 & 61 & 21 & 7 & 79 & 6 & 47 & 2.6 & 943\end{array}$

$\begin{array}{llllllllllll}\text { Working class } & 13 & 3 & 15 & 54 & 12 & 2 & 70 & 5 & 36 & 2.0 & 1329\end{array}$

$\begin{array}{llllllllllll}\text { Farming population } & 21 & 1 & 21 & 53 & 13 & 2 & 56 & 2 & 21 & 1.7 & 387\end{array}$

Family income:

$\begin{array}{lrrrrrrrrrrr}\text { Low } & 18 & 6 & 15 & 47 & 9 & 2 & 62 & 2 & 25 & 1.7 & 805 \\ \text { Low medium } & 13 & 3 & 19 & 55 & 13 & 4 & 68 & 3 & 40 & 2.0 & 640 \\ \text { High medium } & 11 & 5 & 25 & 63 & 16 & 3 & 75 & 5 & 43 & 2.3 & 663 \\ \text { High } & 8 & 5 & 28 & 61 & 24 & 8 & 81 & 10 & 48 & 2.6 & 659\end{array}$

Residence

\begin{tabular}{lrrrrrrrrrrr}
$\begin{array}{l}\text { Urban (total) } \\
\quad\end{array}$ & 11 & 5 & 22 & 56 & 16 & 5 & 73 & 6 & 43 & 2.3 & 1568 \\
$\begin{array}{l}\text { Southern } \\
\text { provinces }\end{array}$ & 13 & 5 & 21 & 55 & 18 & 5 & 72 & 7 & 44 & 2.3 & 1119 \\
$\begin{array}{l}\text { Other } \\
\text { provinces }\end{array}$ & 8 & 5 & 25 & 58 & 11 & 4 & 78 & 4 & 40 & 2.3 & 449 \\
$\begin{array}{c}\text { Rural (total) } \\
\quad \begin{array}{l}\text { Southern } \\
\text { provinces }\end{array}\end{array}$ & 15 & 2 & 21 & 55 & 14 & 3 & 68 & 3 & 31 & 2.0 & 1261 \\
$\quad 14$ & 1 & 21 & 59 & 16 & 3 & 69 & 5 & 34 & 2.1 & 606 \\
$\quad \begin{array}{l}\text { Other } \\
\text { provinces }\end{array}$ & 15 & 3 & 21 & 51 & 12 & 2 & 66 & 1 & 29 & 1.9 & 655 \\
$\quad$ & & & & & & & & & & & \\
eligiosity & 17 & 4 & 20 & 54 & 14 & 5 & 62 & 4 & 30 & 1.9 & 1114 \\
$\begin{array}{l}\text { Strong } \\
\text { Weak }\end{array}$ & 10 & 4 & 23 & 57 & 16 & 3 & 76 & 5 & 43 & 2.3 & 1716 \\
\hline
\end{tabular}


$\mathrm{Table} 2$. Conception control categories and currently used contraceptive Question: "What method of birth control have you been using A two-column code was used, allowing coding for combinations combinations (or alternative use) have here been included in the

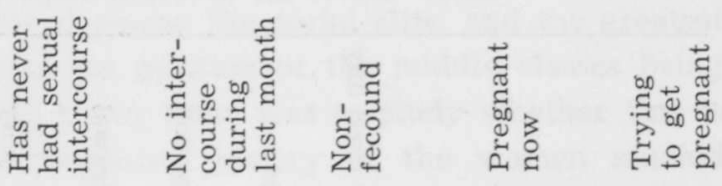

Total

10

11

5

3

Age: $18-20$

$$
\begin{aligned}
& 21-24 \\
& 25-29 \\
& 30-34 \\
& 35-39 \\
& 40-44
\end{aligned}
$$

28
12
6
5
3
6

19

13

8

10

8
11

7
0
0
4
8
11
20

$\begin{array}{rl}5 & 1 \\ 8 & 4 \\ 10 & 5 \\ 4 & 3 \\ 1 & 3 \\ 1 & 1\end{array}$

Marital status and age:

$\begin{array}{ll}\text { Married } & 18-29 \\ & 30-44 \\ \text { Single } & 18-20 \\ & 21-24 \\ & 25-29\end{array}$

$\begin{array}{rr}0 & 4 \\ 0 & 5 \\ 34 & 21 \\ 28 & 27 \\ 32 & 19\end{array}$

$\begin{array}{rrr}3 & 14 & 6 \\ 14 & 3 & 3 \\ 0 & 2 & 1 \\ 0 & 1 & 0 \\ 0 & 0 & 3\end{array}$

Residence by administrative province

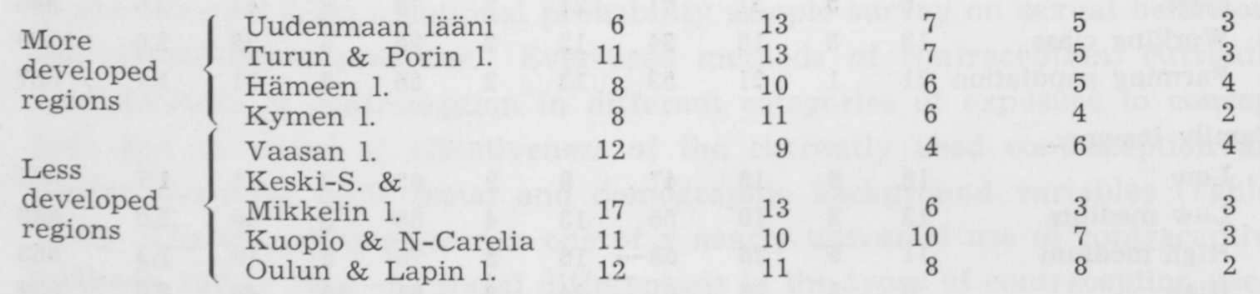

Years of schooling

$$
\begin{array}{r}
-8 \\
9-11
\end{array}
$$

$\begin{array}{rr}6 & 9 \\ 9 & 14 \\ 20 & 13\end{array}$

$\begin{array}{ll}4 & 4 \\ 7 & 3 \\ 6 & 2\end{array}$

Class identification

Upper or middle

Working class

Farming population

$\begin{array}{ll}6 & 3 \\ 6 & 3 \\ 6 & 4\end{array}$

Family income
Low
Low medium
High medium
High

$\begin{array}{rrrrr}17 & 18 & 7 & 4 & 2 \\ 9 & 8 & 6 & 6 & 3 \\ 4 & 6 & 5 & 7 & 3 \\ 4 & 8 & 9 & 6 & 4\end{array}$


methods of the Finnish female population aged 18 to 44 (percentages by row). with your partner during the last month (30 days). Circle all methods used". of two methods. For the sake of simplicity in presentation the cases with category of the more reliable method.
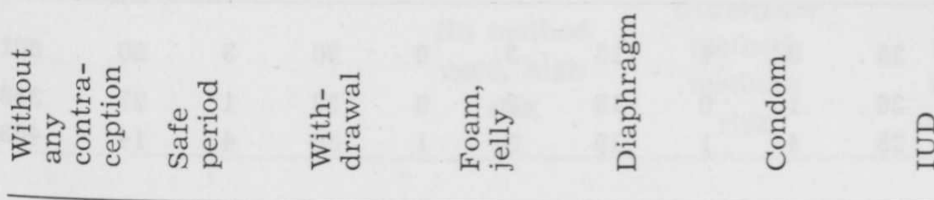

$\exists$

乙

3

1

12

\begin{abstract}
2
\end{abstract}
0

27

2

17

1184

$\begin{array}{ll}1 & 0 \\ 1 & 0 \\ 2 & 0 \\ 4 & 1 \\ 3 & 1 \\ 3 & 2\end{array}$

5
8

1

25

24

30

28

29

19

3

0
0
0
1
1
0

0
0
2
5
3
3

15
29
18
16
16
6

185

229

230

205

178
157

23

1
4
1
2
0

10
19
5
9
14

3
3
0
0
0

0
1
0
0
0

32

30

25

16

16

27
14
11
17
16

338

463

154

98

37

3
2
4
2
2
1
1
3

$\begin{array}{ll}10 & 2 \\ 12 & 2 \\ 10 & 2 \\ 16 & 1 \\ 20 & 1\end{array}$

2
2
2
1
1

28

28
29

29
29

29
30

12

16

20

24

21

$\begin{array}{rrr}3 & 20 & 263 \\ 1 & 15 & 209 \\ 2 & 17 & 166 \\ 2 & 18 & 89 \\ 1 & 12 & 110 \\ & & \\ 2 & 12 & 101 \\ 1 & 16 & 92 \\ 4 & 19 & 145\end{array}$

4
1
1

17
10
6

3
2
1

26

30
24

$\begin{array}{ll}2 & 16 \\ 2 & 18 \\ 2 & 18\end{array}$

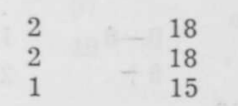

2
1
2
2

0
0
0
1

18
28
31
33

$\begin{array}{ll}0 & 15 \\ 1 & 21 \\ 3 & 19 \\ 5 & 17\end{array}$


$\mathrm{Table} 3$. Currently used contraceptive methods of Finnish married women aged 18 to 44 (percentages by row).

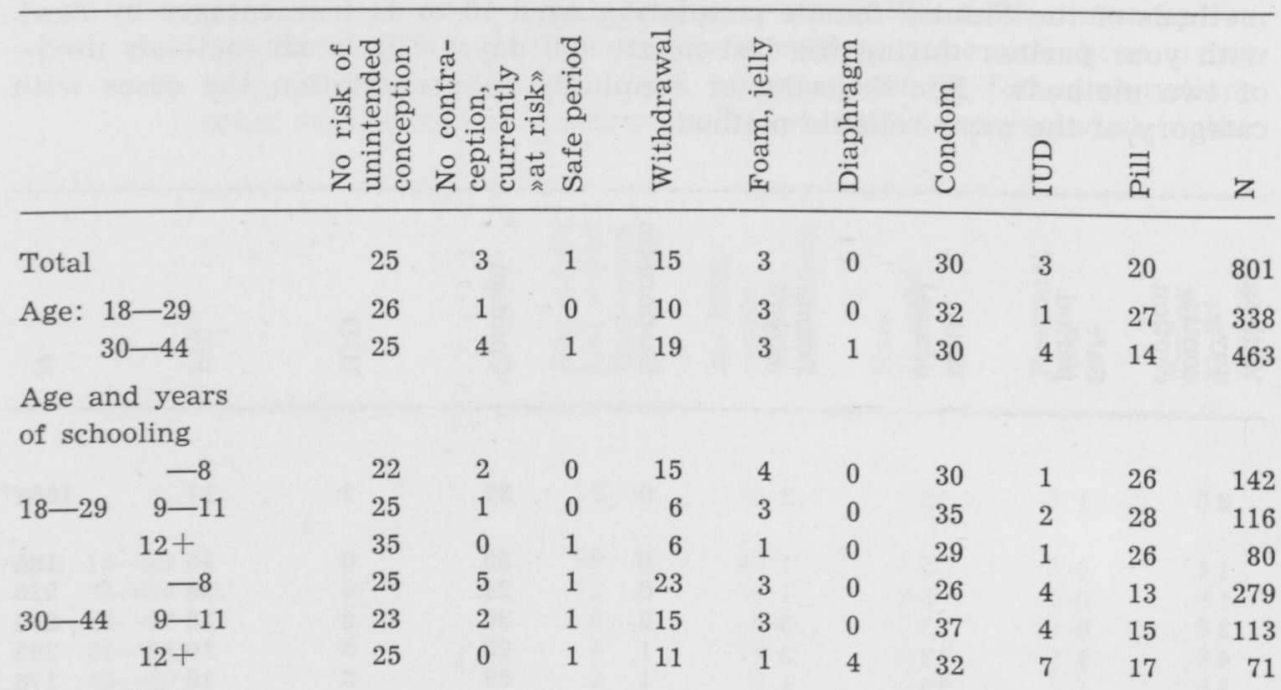

Age and class

identification:

$\begin{array}{llllllllll}\text { Upper \& middle } 27 & 1 & 1 & 8 & 2 & 0 & 34 & 2 & 26 & 131\end{array}$

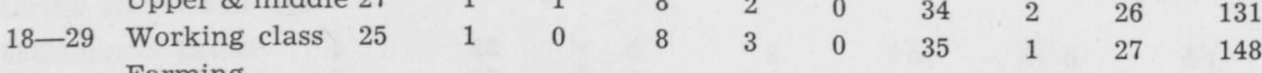

Farming

$\begin{array}{lllllllllll}\text { population } & 29 & 3 & 0 & 13 & 10 & 0 & 13 & 3 & 29 & 43\end{array}$

$\begin{array}{llllllllll}\text { Upper \& middle } 25 & 2 & 1 & 14 & 2 & 2 & 34 & 6 & 14 & 174\end{array}$

$\begin{array}{llllllllllll}30-44 & \text { Working class } & 21 & 5 & 2 & 22 & 4 & 0 & 28 & 5 & 14 & 187\end{array}$

Farming

$\begin{array}{lllllllllll}\text { population } & 40 & 1 & 0 & 30 & 1 & 0 & 19 & 0 & 13 & 68\end{array}$

Family income

$\begin{array}{lllllllllll}\text { Low } & 32 & 3 & 1 & 20 & 4 & 0 & 20 & 1 & 19 & 186 \\ \text { Low medium } & 22 & 2 & 0 & 15 & 2 & 0 & 33 & 2 & 25 & 158 \\ \text { High medium } & 21 & 4 & 1 & 17 & 3 & 0 & 32 & 4 & 18 & 214 \\ \text { High } & 27 & 2 & 1 & 10 & 2 & 1 & 34 & 6 & 18 & 222\end{array}$

Age and religiosity

$\begin{array}{llrllrllllll}18-29 & \text { Strong } & 30 & 3 & 0 & 11 & 4 & 0 & 34 & 2 & 15 & 125 \\ & \text { Weak } & 23 & 0 & 0 & 9 & 2 & 0 & 30 & 1 & 33 & 212 \\ 30-44 & \text { Strong } & 27 & 4 & 2 & 22 & 2 & 0 & 25 & 4 & 13 & 230 \\ & \text { Weak } & 23 & 3 & 0 & 16 & 3 & 1 & 34 & 4 & 16 & 230\end{array}$

Family intentions and

years of schooling

Years of schooling

\begin{tabular}{|c|c|c|c|c|c|c|c|c|c|c|c|}
\hline $\begin{array}{l}\text { Wants no } \\
\text { more }\end{array}$ & $0-8$ & 17 & 5 & 1 & 22 & 4 & 0 & 26 & 4 & 22 & 249 \\
\hline $\begin{array}{l}\text { children } \\
\text { Wants one }\end{array}$ & $9+$ & 21 & 1 & 1 & 12 & 2 & 1 & 35 & 6 & 21 & 166 \\
\hline or more & $0-8$ & 30 & 3 & 1 & 18 & 3 & 0 & 31 & 1 & 13 & 153 \\
\hline $\begin{array}{l}\text { additional } \\
\text { children }\end{array}$ & $9+$ & 28 & 1 & 1 & 8 & 3 & 1 & 34 & 2 & 22 & 193 \\
\hline $\begin{array}{l}\text { Communica } \\
\text { sexual mat } \\
\text { marriage }\end{array}$ & $\begin{array}{l}\text { on about } \\
\text { s in }\end{array}$ & & & & & & & & & & \\
\hline Difficult & impossible & 38 & 1 & 1 & 22 & 3 & 0 & 16 & 8 & 11 & 76 \\
\hline Not so di & cult & 25 & 2 & 1 & 16 & 3 & 0 & 30 & 3 & 20 & 308 \\
\hline Easy and & pen & 23 & 3 & 0 & 13 & 3 & 1 & 34 & 2 & 20 & 410 \\
\hline
\end{tabular}


$\mathrm{T} \mathrm{a} \mathrm{ble} \mathrm{4.} \mathrm{Categories} \mathrm{of} \mathrm{contraceptive} \mathrm{effectiveness} \mathrm{and} \mathrm{the} \mathrm{risk} \mathrm{of} \mathrm{unintend-}$ ed conception among Finnish married women aged 18 to 44 . (Percentages by row. For explanation of risk and contraception categories, see text.)

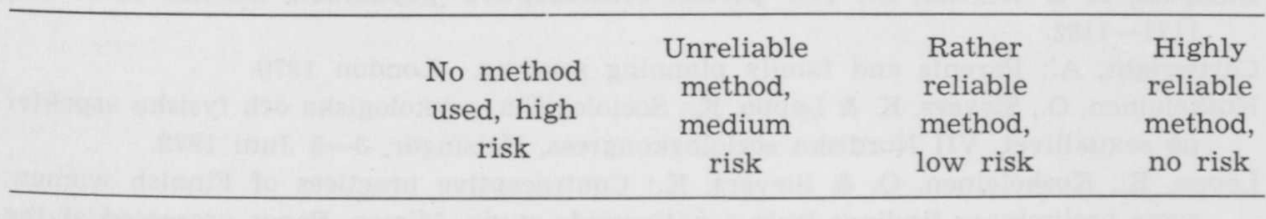

Total

4

21

44

31

Age: $18-29$

1

14

47

38

$30-44$

5

27

24

Age and years of schooling

$\begin{array}{cccrcc}18-29 & -8-11 & 3 & 19 & 43 & 35 \\ & 12+ & 1 & 8 & 51 & 40 \\ & -8 & 0 & 11 & 46 & 42 \\ 30-44 & 9-11 & 7 & 32 & 38 & 23 \\ & 12+ & 3 & 21 & 52 & 25 \\ & & 0 & 16 & 49 & 32\end{array}$

Class identification

Upper \& middle

3

50

31

Working class

4

44

30

Farming population

3

32

29

Family income

Low

Low medium

High medium

High

15

Family intentions and years of schooling

$\begin{array}{llllll}\text { Wants no } & -8 & 6 & 28 & 36 & 31 \\ \text { more children } & 9+ & 1 & 16 & 48 & 34 \\ \text { Wants one or more } & -8 & 5 & 33 & 37 & 23 \\ \text { additional children } & 9+ & 4 & 21 & 49 & 26\end{array}$

Communication about sexual matters in marriage:

Difficult or impossible

Not so difficult

Easy and open 


\section{References}

Acsadi, G., Klinger, A. \& Szabady, E.: Survey techniques in fertility and family planning research. Central Statistical Office, Budapest 1969.

Bumpass, L. \& Westoff, C.: The 'perfect contraceptive' population. Science 1970: 169: $1177-1182$.

Cartwright, A.: Parents and family planning services. London 1970.

Koskelainen, O., Sievers, K. \& Leppo, K.: Sociologiska, psykologiska och fysiska aspekter på sexuallivet. VII Nordiska sociologkongress, Helsingör, 3-5 Juni 1972 .

Leppo, K., Koskelainen, O. \& Sievers, K.: Contraceptive practices of Finnish women: some preliminary findings from a nationwide study. Mimeo. Paper presented at the Nordic Demographic Symposium, Tuusula, Finland 18-20 June 1973.

Leppo, K., Koskelainen, O. \& Sievers, K.: Methodology of the HLH-study. Design, execution and evaluation of the data collection in a multipurpose survey with special reference to sexual behaviour and contraceptive practices of the Finnish adult population. Mimeo. Population Research Institute, Helsinki 1973.

National Board of Health: Circular letter D. No. 10868/09/72 concerning guidance in fertility regulation in primary health care under the Public Health Act.

Rainwater, L.: Family design. Chicago 1965.

Rainwater, L.: Sexual behaviour and family planning in the lower class. In: Human sexuality in medical education and practice. Ed. by C. Vincent, Springfield 1968.

Ryder, N.: Comment. In: New economic approaches to fertility. Ed. by T. W. Schultz, J. Polit. Econ. 1973: 81,2, II: S1-S300.

Ryder, N. \& Westoff, C.: Reproduction in the United States 1965. Princeton 1971.

Sievers, K., Koskelainen, O. \& Leppo, K.: Sexual behaviour and contraceptive practices among the Finnish adult population. Paper presented at the Fifth Meeting of the Working Group on Social Demography. United Nations, Geneva, April 1971. UN/ SOA/WG/2/CONF.5/WP7.

Sievers, K., Koskelainen, O. \& Leppo, K.: A short summary of the developments of the research project on sexual behaviour and contraceptive practices among Finnish adult population. Unpublished background paper for the Sixth Meeting of the Working Group on Social Demography, London, April 1972. Population Research Institute, Helsinki, February 1972.

Sievers, K., Koskelainen, O. \& Leppo, K.: A study on health, living habits and human relations (HLH), with special reference to sexual behaviour and contraceptive practices of the Finnish adult population. A note on a research project in progress, delivered in an informal meeting at the IPPF Europe Region's conference in Turku, Finland, 3-9 June 1973.

Sievers, K., Koskelainen, O. \& Leppo, K.: Suomalaisten sukupuolielämä (Sexual life of Finns). Porvoo 1974 (in print).

Ussing, J. \& Bruun-Schmidt, H.: Nogle resultater fra fertilitetsundersøgelsen. Socialforskningsinstituttet, studie 22. København 1972.

Visuri, E. \& Ritamies, M.: Family planning goals and motives of Finnish men and women. Mimeo. Paper presented at the Nordic Demographic Symposium, Tuusula, Finland, 18-20 June 1973.

Zetterberg, H.: Om sexuallivet i Sverige. SOU 1969: 2. Stockholm 1969. 